\title{
The incidence of ultrasound diagnosed uterine abnormalities related to miscarriage rates - a local audit
}

\author{
Alyaa M. RAHEEM ${ }^{1}$, Hayder A. Al-SHIMMARI ${ }^{1}$, Shatha K. Abdul KAREEM ${ }^{2}$ \\ ${ }^{1}$ Department of Radiography, Faculty of Health and Medical Technology, Baghdad, Iraq \\ ${ }^{2}$ Department of Community Health, Faculty of Health and Medical Technology, Baghdad, Iraq
}

\begin{abstract}
Introduction. Uterine abnormalities are traditionally presented as the cause of pregnancy loss at specific time of pregnancy, mostly at the first or second trimester. The aim of the current study is to use ultrasound to identify the relationship between the incidence of uterine abnormalities and miscarriage at different stages of pregnancy.

Patient and method. 174 cases of women with miscarriage have been examined by transabdominal and transvaginal ultrasound. The patient age was from (18 to 45) years and the data collected over eight month from five different hospitals.

Results. The age group of (26-35 years) has the largest percentage of miscarriage among other tested age groups with $40.8 \%$ in (71cases). Also it was found that single miscarriage was presented in most of the cases. Miscarriage in women with uterine abnormalities was found in $46.6 \%$ of the cases. The major uterine anomalies were bicornuate, septate, arcuate and unicornuate uterus which present in $(24.69 \%, 19.75 \%, 9.88 \%$ and, $7.41 \%)$ respectively. Other ultrasound findings were fibroid, cervical incompetence and endometriosis which occur in $(14.81 \%, 13,58 \%$ and, 9.88\%) correspondingly.

Conclusions. Pregnancy loss is likely to occur in women with bicornuate and septate uterus more than any other uterine anomalies, while the incidences are fewer in women with unicornuate uterus. Furthermore, uterine fibroid is present to be one of the major uterine diseases which can have negative impact on pregnant women, also cervical incompetence and endometriosis are considered as important factors, which can cause pregnancy loss that required further evidence.
\end{abstract}

Keywords: uterine abnormalities, ultrasound, pregnancy

\section{INTRODUCTION}

Ultrasound (US) is one of the most widely used imaging technologies in medicine $[1,2]$. It is an imaging modality that makes tomographic images and collects information about the biological organs. It has several facilities make it the first choice in the diagnosis of soft tissues. The main advantages of ultrasound are: it can be transportable, painless and do not required needles or injections, inexpensive, in addition there is no ionizing radia- tion making it as one of the safer method for the pregnant women scanning $[3,4]$.

Ultrasound scanning can be used in the assessment of female reproductive system at different stages of a woman's age mainly at the menstrual cycle and menopause. Pelvic ultrasound helps in establishing diagnosis of uterine and ovarian malformations, benign or malignant tumors, pelvic inflammatory disease (PID), pelvic ascites, tubo-ovarian abscesses and evaluation of the ovulatory function $[5,6]$. However, the interpretation of 
the findings requires excessive experience of the pelvic organs anatomy and pathology in ultrasound [7]. Furthermore, sonohystography (SHG), is a technique done by inserting a small amount of sterile saline solution into the uterus cavity, which can be used to study the internal structure of the uterus and fallopian tubes [8]. Also, many types of US examinations could add further diagnostic information of the pelvic region such as: standard gray scale, 3D ultrasound, or color Doppler ultrasonography [9]. Especially the uterine abnormalities which is considered one of the causes of infertility or recurrent miscarriage [10]. Uterine abnormalities may not be indicated unless women suffered from symptoms such as miscarriages or abnormal menstrual cycle. Female genital tract ultrasound can be performed either by transabdominal with $3.5 \mathrm{MHz}$ transducer, or with transvaginal 6.5-7.5 $\mathrm{MHz}$ transducer $[4,11]$.

According to the Iraqi Board for Medical Specializations library, there was no previous local evidence cover all the subject of this research. However, some studies have been dealt with one or two types of uterine abnormalities such as uterine fibroid, cervical incompetence $(\mathrm{Cl})$, or specialized in uterine anomalies [12].

\section{METHOD}

A number of techniques have been developed to identify uterine abnormality. This study used two dimensional (2D) ultrasound procedures in order to identify the uterine malformation in 174 cases of women with miscarriage. The patient age was from 18 to 45 years. The data collected from September 2015 to April 2016. They were taken from five places, Baghdad Teaching Hospital, Radi- ation Institution, Al-Zahraa Gynecologic Hospital in Baghdad and two private clinics.

The patients who have one or more pregnancy loss were included in the study whether they have uterine abnormality or not. They should have at least ultrasound scanning during their pregnancy to confirm real intrauterine pregnancy before they loss their fetus. On the other hand, patients who have only positive pregnancy test with specific miss period and Patients who have uterine abnormalities which are treatable at early stage of pregnancy were considered as not relevant to be included. For example, women who had cervical cerclage for the $\mathrm{Cl}$ were excluded.

All patients were examined by ultrasound with transabdominal and transvaginal technique. 2D ultrasound was used to provide information regard the types, shape, size and place of any abnormalities.

\section{ULTRASOUND TECHNIQUE}

The patients were requested to ultrasound exam by the physician according to the specific questioner about their history including previous scanning, miscarriage, infertility, pregnancy test or threatened abortion. Ultrasound exam includes both transabdominal and transvaginal US to assess the types of uterine abnormality as shown in (figure 1). In transabdominal US the patient should fill the bladder to obtain clear image as full bladder moves bowel out from the pelvis into the abdomen, helping in visualization of the uterus and ovaries [2]. Small amount of gel put on the transducer or on the pelvic area to make better contact with skin [13]. The scan was performed through the lower abdomen by moving the transducer over the pelvis on the skin surface in longitudinal

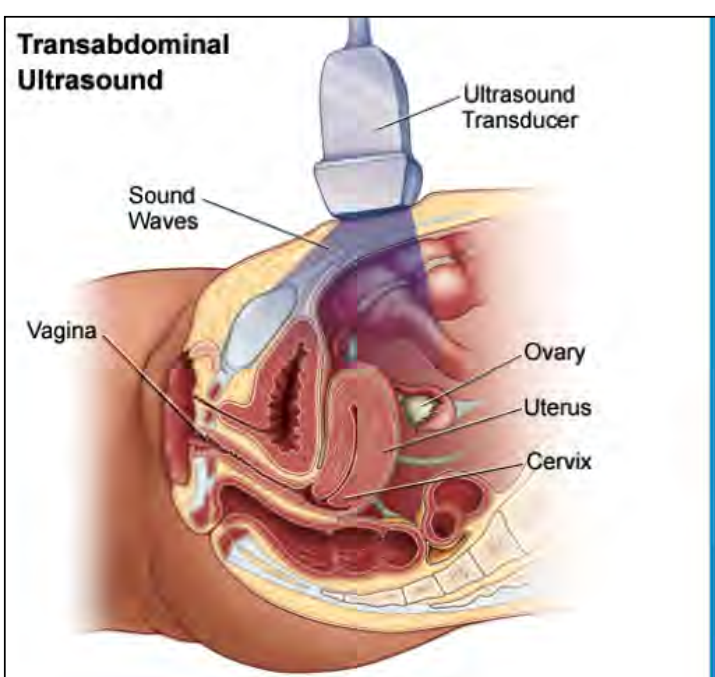

(A) Transabdominal US

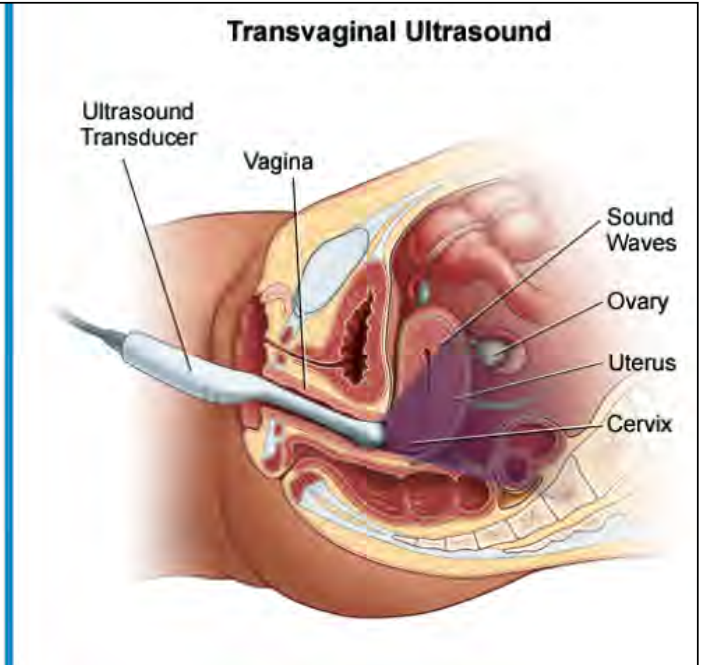

(B) Transvaginal US

FIGURE 1. Types of US technique [33] 
and transverse plane. Curvilinear 3.5 MHz transducer was used for this purpose because this type of frequency has deep penetration which provides better visualization of the pelvic area $[2,3]$.

In transvaginal $U / S$ the patient should avoid the bladder. Small amount of gel was applied on the probe, then transducer wand inserted directly into the vagina using 6.5-7.5 $\mathrm{MHz}$ transducer which considered high frequencies with low penetration to visualize the uterus more closely and get better image details $[2,7,13]$.

\section{RESULTS}

Simple statistical analysis was used to analyze the result quantitatively. In this study, 174 women with one or more abortion were scanned by ultrasound. Some of the patients were found to be suffering from one of the uterine abnormalities, others were normal. The distribution of the cases is presented with the tables and figures below.
Table 1 and Figure 2 show that the abortion were classified into three categories; single, 2-3 and $<3$ abortion. Miscarriage is mainly occurring among age group of 26 to 35 years with 71 cases or $40.8 \%$ of cases and its shows significant correlation. The majority of the cases about 35 cases suffering from single abortion followed by 2-3 abortion which was recorded in 31 cases, while $<3$ abortions are present in few of the cases with only 6 patients.

As can be seen from table 2 , the largest ratio of abortion are presented in women with normal uterus approximately 53.4\% (93 cases), while uterine abnormalities are found in (46.6\%) 81 of cases. Also it demonstrates that single abortion has the largest percentage in both present and absent of uterine abnormalities.

Table 3 demonstrates that $53.4 \%$ of the patients with miscarriage were diagnosed as normal with pelvic ultrasound. Also, women with single abortion represent the majority of the cases in

TABLE 1. Relationship between the number of abortion and age group

\begin{tabular}{|l|c|c|c|c|c|c|c|c|c|c|}
\hline \multirow{2}{*}{$\begin{array}{l}\text { Age groups } \\
\text { in years }\end{array}$} & \multicolumn{2}{|c|}{ Single Abortion } & \multicolumn{2}{|c|}{ 2-3 Abortions } & \multicolumn{2}{|c|}{ >3 Abortions } & \multicolumn{2}{|c|}{ Total } & \multirow{2}{*}{ M.S. } & Sig. \\
\cline { 2 - 13 }$n$ & No. & $\%$ & No. & \% & No. & \% & No. & \% & & \\
\hline $\mathbf{1 8 - 2 5}$ & 33 & 37.1 & 19 & 26.8 & 3 & 21.4 & 55 & 31.6 & $\mathbf{2 . 5}$ & H.S. \\
\hline $\mathbf{2 6 - 3 5}$ & 35 & 39.3 & 31 & 43.7 & 5 & 35.7 & 71 & 40.8 & $\mathbf{2 . 4}$ & S. \\
\hline $\mathbf{3 6 - 4 5}$ & 21 & 23.6 & 21 & 23.6 & 6 & 42.9 & 48 & 27.6 & $\mathbf{2 . 3}$ & S. \\
\hline Total & 89 & 100.0 & 71 & 100.0 & 14 & 100.0 & 174 & 100.0 & $\mathbf{2 . 4}$ & S. \\
\hline
\end{tabular}

$\mathrm{MS}=$ mean of score; $\mathrm{HS}$ =high significant; $\mathrm{S}=$ significant

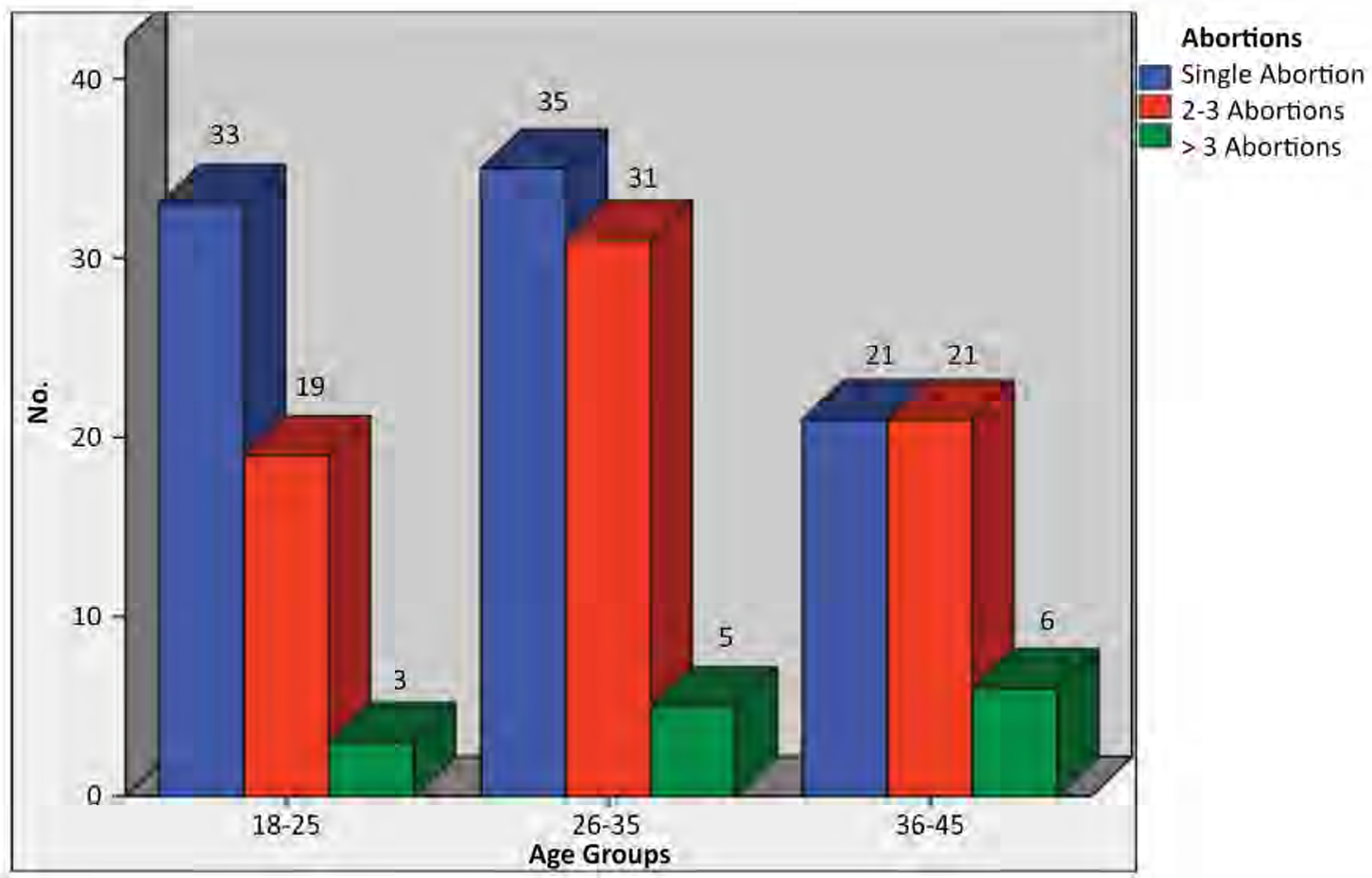

FIGURE 2. Distribution of number of abortions according to age groups 
TABLE 2. Relationship between number of abortions and presence of uterine abnormality

\begin{tabular}{|c|c|c|c|c|c|c|c|c|c|c|}
\hline \multirow{3}{*}{$\begin{array}{l}\text { Uterine } \\
\text { Abnormality }\end{array}$} & \multicolumn{10}{|c|}{ Number of miscarriage } \\
\hline & \multicolumn{2}{|c|}{ Single Abortion } & \multicolumn{2}{|c|}{ 2-3 Abortions } & \multicolumn{2}{|c|}{ >3 Abortions } & \multicolumn{2}{|c|}{ Total } & \multirow[t]{2}{*}{ M.S. } & \multirow[t]{2}{*}{ Sig } \\
\hline & No. & $\%$ & No. & $\%$ & No. & $\%$ & No. & $\%$ & & \\
\hline Present & 42 & 47.2 & 32 & 45.1 & 7 & 50.0 & 81 & 46.6 & 2.43 & S. \\
\hline Absent & 47 & 52.8 & 39 & 54.9 & 7 & 50.0 & 93 & 53.4 & 2.43 & S. \\
\hline Total & 89 & 100 & 71 & 100 & 14 & 100 & 174 & 100 & 2.43 & S. \\
\hline
\end{tabular}

TABLE 3. Ultrasound finding in each type of abortions

\begin{tabular}{|l|c|c|c|c|c|c|c|c|}
\cline { 2 - 8 } \multicolumn{1}{c|}{} & \multicolumn{9}{c|}{ Abortions } & \multicolumn{2}{c|}{} \\
\hline \multirow{2}{*}{ Uterine Abnormalities } & \multicolumn{3}{c|}{ Single Abortion } & $2-3$ Abortions & $>3$ Abortions & \multicolumn{2}{c|}{ Total } \\
\cline { 2 - 9 } & No. & $\%$ & No. & $\%$ & No. & $\%$ & No. & $\%$ \\
\hline Normal & 47 & 52.8 & 39 & 54.9 & 7 & 50.0 & 93 & 53.4 \\
\hline Bicournuate & 10 & 11.2 & 7 & 9.9 & 3 & 21.4 & 20 & 11.5 \\
\hline Unicornuate & 4 & 4.5 & 2 & 2.8 & 0 & 0.0 & 6 & 3.4 \\
\hline Septate & 7 & 7.9 & 8 & 11.3 & 1 & 7.1 & 16 & 9.2 \\
\hline Arcuate & 3 & 3.4 & 5 & 7.0 & 0 & 0.0 & 8 & 4.6 \\
\hline Endometriosis & 4 & 4.5 & 3 & 4.2 & 1 & 7.1 & 8 & 4.6 \\
\hline Cervical Incompetence & 6 & 6.7 & 3 & 4.2 & 2 & 14.3 & 11 & 6.3 \\
\hline Uterine Fibroid & 8 & 9.0 & 4 & 5.6 & 0 & 0.0 & 12 & 6.9 \\
\hline Total & 89 & 100.0 & 71 & 100.0 & 14 & 100.0 & 174 & 100.0 \\
\hline
\end{tabular}

TABLE 4. The relationship between uterine abnormalities and types of abortion

\begin{tabular}{|l|c|c|c|c|c|c|c|c|c|c|}
\hline \multirow{3}{*}{ Uterine Abnormalities } & \multicolumn{9}{|c|}{ Abortions } & \multicolumn{4}{|c|}{} \\
\cline { 2 - 13 } & Single Abortion & $2-3$ Abortions & \multicolumn{2}{|c|}{ 3 Abortions } & \multicolumn{4}{|c|}{ Sig. } \\
\cline { 2 - 13 } & No. & $\%$ & No. & $\%$ & No. & $\%$ & Total & $\%$ & M.S. & S \\
\hline Bicornuate & 10 & 11.2 & 7 & 9.9 & 3 & 21.4 & 20 & 11.5 & 2.3 & S. \\
\hline Unicornuate & 4 & 4.5 & 2 & 2.8 & 0 & 0.0 & 6 & 3.4 & 2.6 & H.S. \\
\hline Septate & 7 & 7.9 & 8 & 11.3 & 1 & 7.1 & 16 & 9.2 & 2.3 & S. \\
\hline Endometriosis & 4 & 4.5 & 3 & 4.2 & 1 & 7.1 & 8 & 4.6 & 2.3 & S. \\
\hline Cervical Incompetence & 6 & 6.7 & 3 & 4.2 & 2 & 14.3 & 11 & 6.3 & 2.3 & S. \\
\hline Uterine Fibroid & 8 & 9.0 & 4 & 5.6 & 0 & 0.0 & 12 & 6.9 & 2.6 & H.S. \\
\hline Arcuate & 3 & 3.4 & 5 & 7.0 & 0 & 0.0 & 8 & 4.6 & 2.3 & S. \\
\hline Total & 42 & 100 & 32 & 100 & 7 & 100 & 81 & 100 & 2.3 & S. \\
\hline
\end{tabular}

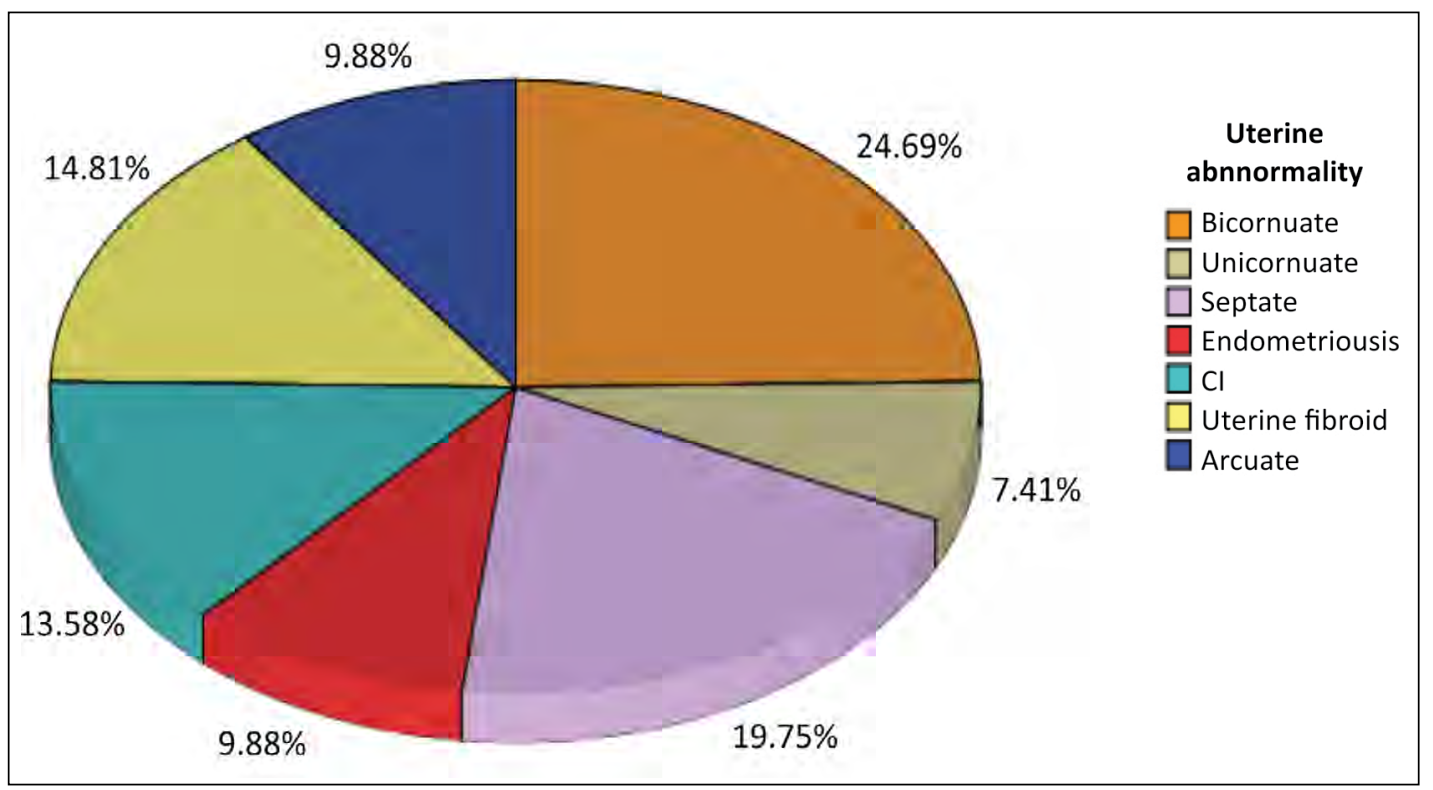

FIGURE 3. Distribution of study sample according to types of uterine abnormalities 
most types of uterine abnormalities. For example, women with bicournuate uterus were recorded in 10 patients with single abortion and in 7 and 3 patients of women with 2-3 and more than 3 respectively.

Table 4 and figure 3 displayed the percentage of uterine abnormalities among female with miscarriage. It is clearly seen that bicornuate uterus occupied higher percentage than other abnormalities, which identified in $24.69 \%$ of the abnormal cases, then septate uterus which noticed in $19.75 \%$. Unicornuate have the least incidence which present in only $7.41 \%$ of abnormal cases.

\section{DISCUSSIONS}

Several factors have been recorded as etiological causes of spontaneous abortions. This study was conducted on women who suffered from at least one miscarriage, then they scanned by ultrasound to diagnose if they have any uterine abnormalities as these are one of the main factors that have been implicated in the occurrence of recurrent miscarriage $[10,14]$.

As shown in tables 1 and figure 2 the greatest percentage of miscarriage was presented in the age group (26-35) whether they were suffering from uterine abnormalities or not. This may be due to the main age of marriage in the area of study as registered by the Iraq Family Health Survey (2007), which identified that the average age of marriage is the age 25year and it is recorded in $55.6 \%$ of married women [12].

Of the total cases of women with abortion about 81 patients or $46.6 \%$ of the cases have uterine abnormalities including congenital and acquired irregularities as shown in table 2 . The most obvious finding to emerge from the analysis is that women with bicornuate uterus have the highest incidence of recurrent pregnancy loss with significant correlation. It is recorded that 20 patients (24.69\%) with one or more miscarriage is likely to have bicornuate uterus, as shown in figure 4 . This represents $11 \%$ of all the collected cases. This result is in consistent with previous studies which indicate that the prevalence of bicornuate uterus has the foremost prevalence among all types of anomalies and it could be found in $37 \%$ of patients with incomplete pregnancy $[15,16]$. However, several studies have stated that frequency of septate uterus is greater than bicornuate uterus [15], while in current study septate uterus present as a second major defect of the uterus, which affected on the reproductive outcome. This defect is present in 16 patients $-9.2 \%$ of all patients with preg- nancy loss or $19.75 \%$ of the patients with uterine abnormality. Such deference in the results may relate to the differential diagnosis in each study which depends on the diagnostic techniques. For example, the diagnosis by 3D ultrasound [34], sonohysterography [35], and MRI can provide more information to differentiate between bicornuate, septate and arcuate uterus [36].

A significant ultrasound finding was uterine fibroid which represents $14.81 \%$ or 12 cases of the patients with spontaneous abortion. These findings will doubtless be much scrutinized, but there are some immediately dependable conclusions for the effect of uterine fibroid on pregnancy outcome. Previous study suggested that $10 \%$ of the patients with uterine fibroid is likely to have spontaneous miscarriage [17], whereas other study has found that only $4.5 \%$ of the females with uterine fibroid will develop pregnancy loss [18]. Other has deferent results and reported that miscarriage rate could reach $33.3 \%$ in patients with intramural fibroid [19]. Currently, not many studies have reported correlation between fibroids and abortion. The overwhelming common studies in the literature reporting an elevation in the rates of abortion in patients with uterine fibroid $[18,20,21]$. Unfortunately, their main concentration was infertility rates rather than miscarriage, while only a small number of researches have made a discrepancy about types of fibroids. For example, there is a systematic review found obvious relationship between the location of fibroids and spontaneous miscarriage rate. Pregnancy loss is likely to be higher with submucosal and intramural respectively compared with women with normal uterus while, subserosal fibroids have hardly any effect on pregnancy [22]. Conversely, some studies established that all types of fibroids may cause spontaneous miscarriage [23].

Other ultrasound finding was cervical incompetence $(\mathrm{Cl})$, in this condition the cervix is considered incompetent when it is unable to support a pregnancy until delivery. Typically, there is no symptom and the dilatation occurs in the second trimester which causes premature delivery $[24,26]$, which considered one of the etiological factors that have negative effect on fetal placentation and can increase risk of miscarriage $[15,25,32]$. $\mathrm{Cl}$ is presented in $13.58 \%$ of all aborted patients with abnormality as shown in figure 4 . However, there is no much up to date evidence concerned with this subject. Old evidences were found that the incidence of $\mathrm{Cl}$ among aborters is from 8 to $15 \%[24,27]$. This condition is mostly treatable at early stage of pregnancy which could decrease the rate of pregnancy loss [37]. 
Both endometriosis and arcuate uterus are noticed in same percentage of $9.88 \%$. Endometriosis is a condition in which endometrial glands are presenting at outside uterus [11]. Women with this condition will be under risk of early miscarriage or later pregnancy complications [10]. Recent study has supported this result and shown that women with endometriosis were $76 \%$ more likely to have a miscarriage than those who did not have the condition [29]. Also, this result is in accord with previous study by Salim et al. (2003), who illustrate that the incidence of arcute uterus is from 1.0 to $16.9 \%$. However, the effect of it on miscarriage remains unexplainable [30].

The final result was the unicornuate uterus which has the least incidence of the causes of miscarriage with $7.41 \%$. This result is approved by $\mathrm{Li}$ et al. (2000), who illustrate that unicornuate uterus has poor impact on pregnancy and present in $4.4 \%$ of the women with recurrent abortion [31]. Other study illustrates that four of five patients with unicornuate will suffer from early pregnancy loss [15].

In general, ultrasound finding of uterine abnormalities was established in $46.6 \%$ of the aborted patients compared with $53.4 \%$ with normal uterus. This high percentage is related to combination of the congenital \& acquired abnormality of the uterus. The prevalence of major uterine anomalies such as bicornuate, unicornuate, septate and arcuate uterus was $28.7 \%$ and acquired abnormalities were about $18 \%$ among all women with miscarriages. These findings were comparable to the finding of the previous research which finds ap- proximately the same results [38]. These results suggest that uterine abnormalities were found in high percentage of Iraqi women, so these data must be carefully interpreted to identify the primary causes such incidence.

\section{CONCLUSIONS}

The present study was designed to determine the prevalence of uterine abnormality in aborted women. The results of this investigation show that less than half of women (46.6\%) have uterine abnormalities and more than half of the cases look normal on ultrasound. The main age group was from 26-35 years with all number of abortions and the majority of the patients $(51 \%)$ have single abortion. The most obvious prevalence of uterine anomalies was bicornute uterus presenting in $\mathbf{2 0}$ patients followed by septate uterus which established in16 of the inspected women. However, only 6 cases of 147 have unicornuate uterus. Other ultrasound findings of the patient with pregnancy loss were uterine fibroid, $\mathrm{Cl}$ and endometriosis which indicated in 14.81\%, $13.58 \%$ and $9.88 \%$ respectively. The empirical findings of this study provide new evidence regard the incidence of uterine anomalies and pathology among women with abortion bases on ultrasound scanning. Therefore, further research needs to examine more closely the links between each type of abnormalities and pregnancy loss. Also it could be carried out on uterine abnormalities using other diagnostic modalities.

Conflict of interest: none declared Financial support: none declared

\section{REFERENCES}

1. Murthi SB, Ferguson M, Sisley AC. Ultrasound physics and equipment. In Bedside Procedures for the Intensivist 2010; 2nd edition pp. 57-80.

2. Palmer Philip ES, Breyer B, Bruguera CA, Gharbi HA, Goldberg BB et al. Manual of diagnostic ultrasound, edited by P. E. S. Palmer, 1995.

3. Wilhjelm JE, Kristensson M, Andersen OT. Medical diagnostic ultrasound physical principles and imaging. Technical University of Denmark. 2016; 1(3). pp1-18. Available at: http://bme.elektro.dtu.dk/jw/webbook/ Ultrasound/main.pdf.

4. Chan V, Perlas A. Basics of Ultrasound Imaging. In: Atlas of Ultrasound-Guided Procedures in Interventional Pain Management. By Narouze, S.N. (eds.). Springer Science and Business Media. 2011; pp.13-19.
5. Canzone G, Parlato M, Triolo L. 2D-3D Ultrasound in the Diagnosis of Uterine Malformations. Donald School Journal of Ultrasound in Obstetrics \& Gynecology. 2007; pp. 77-79.

6. Scanlon VC, Sanders T. Essentials of Anatomy and Physiology 4th edition, FA Davis Company. ISBN. Journal of medical education 2007; 30(5). 13: 978-0-80363957-7@ 2015 Paperback 696 pages.

7. Mihu D, Mihu CM. Ultrasonography of the uterus and ovaries. Medical Ultrasonography. 2011; 13(3), pp. 249-52.

8. Bermejo $\mathrm{C}$ et al. Three-dimensional ultrasound in the diagnosis of Müllerian duct anomalies and concordance with magnetic resonance imaging. Ultrasound in Obstetrics and Gynecology, 2010; 35(5), pp. 593-601.

9. Momtaz MM, Ebrashy AN, Marzouk AA. Three-dimensional ultrasonography in the evaluation of the uterine cavity. Middle East Fertility Society Journal. 2007; 12(1), pp. 41-46.

10. Rackow BW, Arici A. Reproductive performance of women with müllerian anomalies. Current Opinion in Obstetrics and Gynecology. 2007; pp. 229-237.

11. Bagaria SJ, Rasalkar DD, Paunipagar BK. Imaging Tools for Endometriosis : Role of Ultrasound, MRI and Other Imaging Modalities in Diagnosis and Planning Intervention. Endometriosis-Basic Concepts and Current Research Trends. 2012; pp. 438-446.

12. WHO Ministry of Planning and Development Cooperation. Iraq Family Health Survey. 2007; Available at http:// www.who.int/mediacentre/news/ releases/2008/pr02/2008_iraq_family_ health_survey_report.pdf. 
13. Lutz H, Buscarini, E. Manual of Diagnostic Ultrasound. World Health Organization. World Federation for Ultrasound in Medicine and Biology. 2011;1(2) ISBN 978 9241547451.

14. Weintraub AY, Sheiner. Early Pregnancy Loss. E. Sheiner (ed.), Bleeding During Pregnancy: A Comprehensive Guide, Journal of Postgraduate Medicine. 2011; Springer Science+Business Media.

15. Sugiura-Ogasawara M et al. Uterine anomaly and recurrent pregnancy loss. Seminars in Reproductive Medicine, 29(6), 2011; pp. 514-521.

16. Raga $\mathrm{F}$ et al. Reproductive impact of congenital Mullerian anomalies. Human Reproduction. 1997; 12(10), pp. 22772281.

17. Poovathi M, Ramalingam R. Maternal and Fetal Outcome in Pregnancy with Fibroids: A Prospective Study. International Journal of Scientific Study. 2016; 3(11), pp. 169-172.

18. MJ et al. Effect of uterine fibroid on pregnancy outcome. Pakistan Journal of Medical and Health Sciences. 2010; pp. 476-478.

19. Hart R, Khalaf Y, Yeong CT, Seed P, Taylor A, Braude P. A prospective controlled study of the effect of intramural uterine fibroids on the outcome of assisted conception. Hum Reprod. 2001 Nov;16(11):2411-7.

20. CB B. et al. Outcome of pregnancies in women with uterine leiomyomas identified by sonography in the first trimester. Journal of Clinical Ultrasound. 2001;pp. 261-264.

21. Morita M. Laparoscopic myomectomy for symptomatic uterine myomas. Journal of the Medical Society of Toho University. 2008; pp. 218-222.
22. Somigliana E et al. Fibroids and female reproduction: A critical analysis of the evidence. Human Reproduction Update. 2007; pp. 465-476.

23. Saravelos $\mathrm{SH}$ et al. The prevalence and impact of fibroids and their treatment on the outcome of pregnancy in women with recurrent miscarriage. Human Reproduction. 2011; 26(12), pp. 3274-3279.

24. Williams WH. Cervical incompetence. American Journal of Obstetrics and Gynecology. 1978; p. 703.

25. Easterday L, Reid E. The New England Journal of Medicine Downloaded from nejm.org at UNL on April 11, 2015; From the NEJM Archive. Copyright @ 2010 Massachusetts Medical Society.

26. Romero $\mathrm{R}$ et al. The role of cervical cerclage in obstetric practice: Can the patient who could benefit from this procedure be identified? American Journal of Obstetrics and Gynecology. 2006; pp. 1-9.

27. Ford HB, Schust, DJ. Recurrent pregnancy loss: Etiology, diagnosis, and therapy. Reviews in Obstetrics \& Gynecology. 2009; 2(2), pp. 76-83.

28. Obeng BB. Cervical incompetence: Surgical treatment of twenty-four cases during pregnancy. Postgraduate Medical Journal. 1967; 43(506), pp. 763-769.

29. Dunselman GAJ et al. ESHRE guideline: Management of women with endometriosis. Human Reproduction. 2014; 29(3), pp. 400-412.

30. Salim R. et al. A comparative study of the morphology of congenital uterine anomalies in women with and without a history of recurrent first trimester miscarriage. Human Reproduction. 2003; 18(1), pp. 162-166.

31. Wallach EE et al. Female genital anomalies, affecting reproduction. Fertility and Sterility. 2002; 78(5):899-915.

32. Au S et al. Midtrimester pregnancy loss and cervical incompetence -Is there an association with connective tissue laxity? Open Journal of Obstetrics and Gynecology. 2014; 04(01), pp. 28-32.

33. John Hopkins Medicine. Pelvic Ultrasound. Health library. Available at http://www. hopkinsmedicine.org/healthlibrary/ test_procedures/gynecology/pelvic_ ultrasound 92,P07784.

34. Woelfer B et al. Reproductive outcomes in women with congenital uterine anomalies detected by three-dimensional ultrasound screening. Obstetrics and Gynecology. 2001; 98(6), pp.1099-1103.

35. Perrot N, Frey I, Bigot JM. Ultrasonohysterography: Techniques and indications. [In French]. J Radiol. 1996; 77(9):687-690.

36. Pellerito JS, McCarthy SM, Doyle MB, Glickman MG, DeCherney AH. Diagnosis of uterine anomalies: Relative accuracy of MR imaging, endovaginal sonography, and hysterosalpingography. Radiology. 1992; 183(3):795-800.

37. Suhag A, Berghella V. Cervical Cerclage Clinical Obstetrics and Gynecology. 2014; 57 (3), 557-567.

38. Grimbizis GF et al. Clinical implications of uterine malformations and hysteroscopic treatment results. Human Reproduction Update. 2001; 7(2), pp. 161-174. 